\title{
Percutaneous endoscopic gastrostomy in children
}

\author{
A single center experience in Saudi Arabia
}

Faisal A. Alhaffaf, MD, Awad S. Alqahtani, MD, Abdulrahman A. Alrobyan, MD, Sarab N. Alqubaisi, MD, Bashar A. Ahmad, MD, Mohammad R. Almutairi, RN1, Sami A. Wali, MD, Hamoud A. Alhebbi, MD.

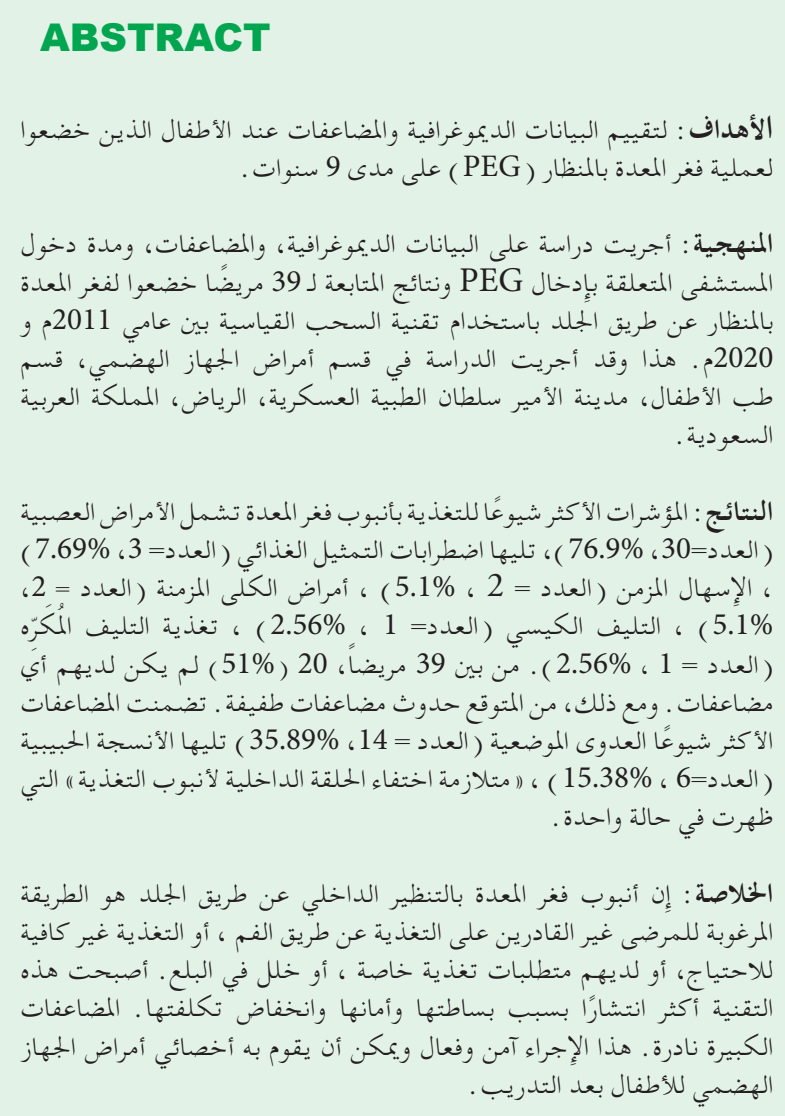

Objectives: To evaluate the demographic data and complications in children who had undergone percutaneous endoscopic gastrostomy (PEG) over 9 years period.

Methods: The demographic data, complications, length of hospital admission related to PEG insertion and follow-up findings of 39 patients who had undergone percutaneous endoscopic gastrostomy using the standard pull-through technique between 2011 and 2020 were examined. The study took place at the Gastroenterology
Division, Department of Pediatrics, Prince Sultan Military Medical City, Riyadh, Saudi Arabia

Results: The most common indications of feeding with a gastrostomy tube include neurological diseases $(n=30$, $76.9 \%)$, followed by metabolic disorders $(n=3,7.69 \%)$, chronic diarrhea $(n=2,5.1 \%)$, chronic kidney diseases $(\mathrm{n}=2,5.1 \%)$, cystic fibrosis $(\mathrm{n}=1,2.56 \%)$, feeding aversion fibrosis $(\mathrm{n}=1,2.56 \%)$. Out of the 39 patients, $20(51 \%)$ did not have any complications. However, minor complication are expected. Most common complications included local infection $(\mathrm{n}=14,35.89 \%)$ followed by granulation tissue $(n=6,15.38 \%)$, "buried bumper syndrome" developed in one.

Conclusion: Percutaneous endoscopic gastrostomy tube is the desirable method for patients who are unable to feed orally, feeding is not adequate for demands, has special feeding requirements, or swallowing dysfunction. The technique has become more widespread because of its simplicity, safety, and low cost. Major complications are rare. The procedure is safe and effective and could be carried out by pediatric gastroenterologists after training.

Keywords: percutaneous, endoscopic, gastrostomy

Saudi Med J 2021; Vol. 42 (2): 205-208 doi: 10.15537/smj.2021.2.25692

From the Gastroenterology Division, Department of Pediatrics (Alhaffaf, Alqahtani, Alqubaisi, Wali, Alhebbi), from the Department of Medicine (Alrobyan), from the Department of Radiology (Ahmad), and from the Endoscopy Unit, Almutairi, Prince Sultan Military Medical City, Riyadh, Kingdom of Saudi Arabia.

Received 11th October 2020. Accepted 9th December 2020.

Address correspondence and reprint request to: Dr. Faisal A. Alhaffaf, Consultant, Pediatric Gastroenterology, Hepatology \& Nutrition, Prince Sultan Military Medical City, Riyadh, Kingdom of Saudi Arabia.E-mail:Dr.faisal.ped@hotmail.com

ORCID ID: https://orcid.org/0000-0002-5322-1398 
T o maintain the normal growth and development of a child, a sufficient energy and nutritional requirements should be provided. Providing sufficient energy and nutrition play a significant role in management of the primary disease. Normally, nutrition is provided orally. However, when energy and nutritional requirements cannot be administered orally, enteral feeding is used. ${ }^{1}$ Nasogastric, nasoenteric tube, gastrostomy (GT), and enterostomy tubes have been used before. It is preferred that enteral feeding is administered through the stomach. Feeding through the stomach is more physiological. ${ }^{2}$ Moreover, pancreatic enzymes functioned and controlled as the passage of the nutrients from the stomach to the small bowel. ${ }^{3} \mathrm{~A}$ gastrostomy tube can be inserted using endoscopically, radiological, or surgical methods. The most common method in pediatric age group is percutaneous endoscopic gastrostomy (PEG), developed by Gauderer in 1980. Nowadays, PEG tube is becoming the preferred method to deliver medication, fluid, and food in children who do not have sufficient oral intake. Previously, the main approach was an open surgical gastrostomy. ${ }^{4}$ In 1980, the first PEG tube insertion was reported. ${ }^{5}$ Since then, it is rapidly becoming the technique of choice. The aim of this study is to evaluate the demographic data, complications, and length of hospital admission in children who had undergone PEG.

Methods. This is a retrospective study of all children who underwent PEG procedure between 2011 and 2020 were included in the study that took place at the Gastroenterology Division, Department of Pediatrics, Prince Sultan Military Medical City, Riyadh, Saudi Arabia. Only 2 patients were excluded after missing their follow up. The International Review Board approval was obtained from the Ethical Committee of Prince Sultan Military Medical City, Riyadh, Saudi Arabia with project number 1299. Demographic data, underlying diseases, indication for insertion, times of PEG change, procedure-related complications, and gastroesophageal reflux disease (GERD) rate were reviewed. The diagnosis of GERD was made mainly on a clinical findings. Medications after PEG insertion (proton pump inhibitor [losec and nexium]

Disclosure. Authors have no conflict of interests, and the work was not supported or funded by any drug company. which packed by tabuk pharmaceutical manufacturing company, Saudi arabia under the license from Astrazeneca $\mathrm{AB}$ and prokinetics [domperidone] which also packed by tabuk pharmaceutical manufacturing company, Saudi arabia). Lengths of hospital stay after insertion and number of admissions related to PEG insertion were also gathered. Abdominal x-rays at 45 degrees were performed before the procedure to assess the presence of the colonic gas in front of the stomach and to assess the presence of scoliosis. The presence of colonic gas in front of the stomach after cleaning the bowel with laxative and presence of peritoneal dialysis were considered contraindication in our center. The procedure was performed using the pull method and requiring 2 physicians. One for endoscopic guidance and the other was for percutaneous interventions. The patient was placed in a supine position and the head was raised 45 degrees to keep the colon below the stomach. Skin sterilization was performed before the introduction of the scope to avoid excessive air, which could have dilated the colon to cross in front of the stomach. After sterilization, the percutaneous entrance was implemented in the epigastric region after considering the light of the endoscope on the skin and the fluctuation sensed by the fingers. A standard PEG set (Kimberly-Clark MIC ${ }^{\circledR}$ PEG size 14 French) or corpack size (12 and 16 French) was initially placed in all patients.

Results. Over a 9-year-period, 39 PEG procedures were performed in 39 children. Twenty eight switched from standard PEG to button and 2 was removed. Twenty-three (59\%) were male. The youngest patient was 5 months of age and the oldest was 12 years (144 months) with a mean age of 53 months. The mean weight was found to be $12 \mathrm{~kg}(3.5-34 \mathrm{~kg})$. The number of patients below 2 years was $12(30.8 \%)$. The mean length of admissions was 3.5 days. The PEG was changed to low profile GT in 17 (43.5\%) of our patients. Percutaneous endoscopic gastrostomy was removed in 2 patients (5\%), One of them recovered from encephalopathy and the other one was removed due to the mother's dissatisfaction. The mean time for switching from the standard PEG to low profile GT was $8 \pm 3.4(5-12)$ months. Indications for change were breakages or family wishes. In this period, 2 patients (5\%) died due to factors related with the underlying diseases. The families of these patients were asked by nutrition nurses who performed follow-up visits whether they would allow their children to have a PEG catheter placed again and a positive answer was obtained from all parents. The most common indications of feeding 
with a gastrostomy tube include neurological diseases, which impair functions, such as sucking, chewing, and swallowing $(\mathrm{n}=30,77 \%)$ followed by metabolic disorders $(n=3,9 \%)$, chronic diarrhea $(n=2,6 \% \%)$, chronic kidney diseases $(n=2,6 \%)$, cystic fibrosis $(n=1$, $3 \%)$, and feeding aversion $(n=1,3 \%)$ as shown in Figure 1.

During the follow-up, one patient with severe onset epileptic encephalopathy with uncontrolled seizures was started on a ketogenic diet after PEG insertion. Currently, his seizures is well controlled. Twenty-seven patients were not able to take their medication for different reasons (recurrent vomiting, recurrent aspiration, or swallowing incoordination) and all of these patients show better compliance with their medications at present. Thirty patients (77\%) have neurological diseases, with sucking, chewing, and swallowing incoordination, which put them at risk of recurrent chest infection. The pediatric intensive care unit admissions, due to respiratory problems, was $2.1 \%$ per year before PEG tube insertion has declined to $0.8 \%$ after PEG insertion. Our patients were examined in terms of gastroesophageal reflux (GER) before the procedure (all patients were questioned about reflux complaints, and the diagnosis of GER was made based on the clinical findings). Few of them had a gastroscopy or 24-hour pH-impedance exam. While the number of patients who used anti-reflux drugs before PEG was 19 (48.7\%), this number was observed to increase to 21 (53.8\%) after PEG tube insertion.

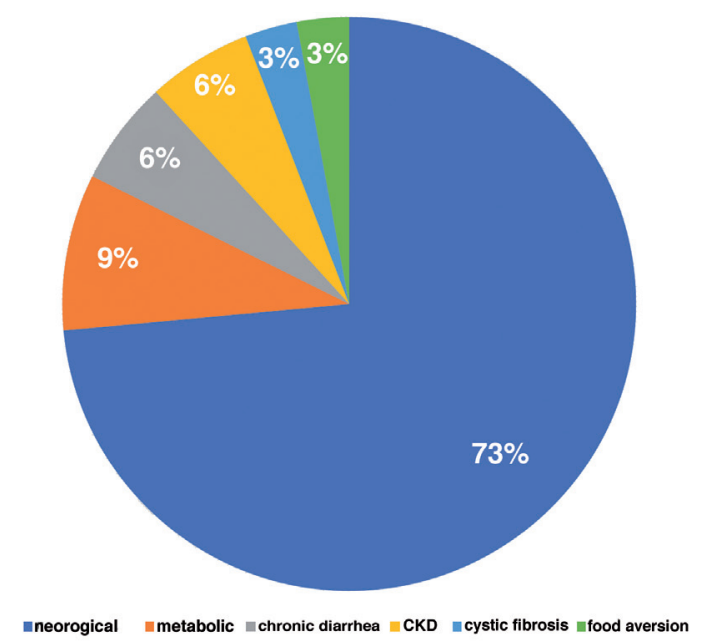

Figure 1 - Indications for percutaneous endoscopic gastrostomy insertion. CKD: chronic kidney disease
Out of the 39 patients, 20 patient (51\%) did not have any complications. However, minor complication are expected after PEG insertion. ${ }^{6,7}$ Most common complications included local infection $(n=14,35.9 \%)$ followed by granulation tissue (6 patients, 15.4\%), leakage $(n=2,5 \%)$, and GT dislodge $(n=1,2.6 \%)$ as shown in Figure 2. Two patients with cerebral palsy had aspiration pneumonia after percutaneous endoscopic gastrostomy insertion. They had undergone Nissen fundoplication. "Buried bumper syndrome" developed in one patient and was removed by pulling it without complication and button PEG low profile gastrostomy tube were placed. One patient developed significant cellulitis and were treated with intravenous antibiotics. The granulation tissue was treated with local silver nitrate cauterization.

Discussion. Percutaneous endoscopic gastrostomy insertion is an endoscopic technique that allows the insertion a tube to create a tunnel between the abdominal wall and the stomach, facilitating passing of medication, fluid, and food into the patient's stomach. ${ }^{8}$ There are a few reports in infants with PEG tubes insertion. ${ }^{9}$ The appropriate body weight for insertion of PEG in the previous guidelines was approximately $10 \mathrm{~kg} .{ }^{10}$ Recent studies have reported the safely in young infants with and can be used in infants below one year of age and a body weight as low as $2.6 \mathrm{~kg} .^{11}$ The youngest patient in our study was 5 months old and weighed $3.5 \mathrm{~kg}$. When 39 patients included in this study was examined, it was noticed that the patients with neurological problems presented the highest indication for PEG insertion. This was compatible with the large series published worldwide. ${ }^{12}$ Because of the high rate of consanguinity in our country, we have high metabolic diseases rate.

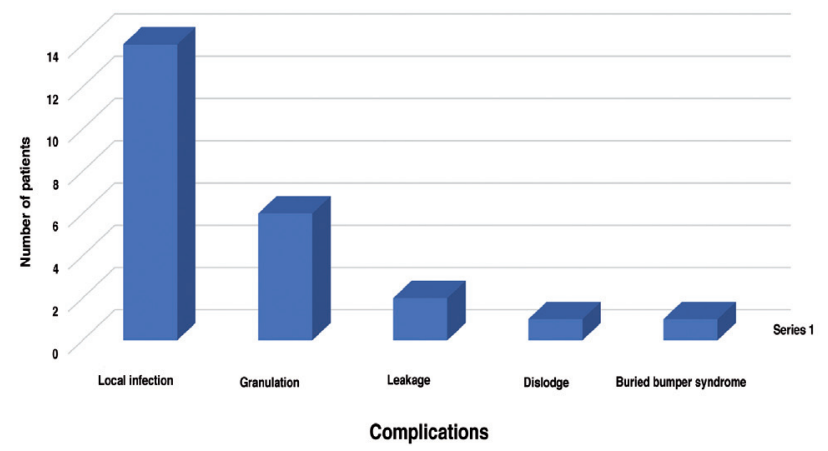

Figure 2 - Complication for percutaneous endoscopic gastrostomy tube insertion. 
Metabolic diseases are the second most common reason for PEG insertion (7.7\%). This is compatible with study carried out by Srinivasan et al, ${ }^{13}$ it was reported that $160(41.6 \%)$ of 384 subjects in whom PEG was placed had neurological problems and $7(1.8 \%)$ had metabolic problems.

In a study by Tugba-Koca et $\mathrm{al}^{8}{ }^{8}$ the number of children who used anti-reflux medications increased from $16(47.1 \%)$ to $18(52.9 \%)$ after insertion of a PEG tube. We also observed an increase in the use of anti-reflux medications after placement of PEG tube from $19(48.7 \%)$ to $21(51.2 \%)$ children. In our study, 2 patients who had recurrent aspiration pneumonia after PEG tube insertion had undergone Nissen fundoplication. Although minimal evidence supported the view that the reflux symptoms increases after PEG insertion, others have reported the opposite. ${ }^{15,16}$ Puntis et $\mathrm{al}^{15}$ recommended that routine anti-reflux medication should not be used in these patients, and investigations for GERD should be avoided in patients without symptoms or signs. However, some of the outcomes could be affected by comorbidities of each patient and this consider a limitation of our study. There are major and minor complications of PEG insertion. Major complications include death, peritonitis, hemorrhage necrotizing fasciitis, and tumor implantation. Minor complications include leakage, local infection, fistula formation, buried bumper syndrome, ulcers, and accidental removal. In general, major complications are rare, while minor complications are proportionally expected. ${ }^{8}$ In a study carried out by Fortunato et $\mathrm{al}^{16}$ on 760 children with a PEG tube, local infection happened in $8 \%$ of the children and granulation tissue happened in $9 \%$ of children. In our study, the most common complication was local infection $(\mathrm{n}=12,30.7 \%)$ followed by granulation tissue $(n=6,15.4 \%)$.

In conclusion, feeding through a PEG tube is the desirable method for patients with dysphagia, those who are unable to feed orally, feeding is not adequate for demands, has special feeding requirements (metabolic or ketogenic diet), or has significant respiratory complications due to swallowing dysfunction despite having a functioning digestive system. The technique has become more widespread because of its simplicity, safety, and low cost. Major complications are rarely observed. The procedure is safe and effective in our country and could be carried out by pediatric gastroenterologists after appropriate training.

Acknowledgment. The authors gratefully acknowledge American Manuscript Editors (https://americanmanuscripteditors.com) for the English language editing.

\section{References}

1. Toporowska-Kowalska E, Gèbora-Kowalska B, Jabłoński J, Fendler W, Wásowska-Królikowska K. Influence of percutaneous endoscopicgastrostomy on gastro-oesophageal reflux evaluated by multiple intraluminal impedance in children with neurological impairment. Dev Med Child Neurol 2011; 53: 938-943.

2. Durakbaşa Ç, Kılıç YE, Pelit M, Şehiralti V, Aksu N, Mutuş $\mathrm{M}$, et al. Percutaneous endoscopic gastrostomy applications in children with nutritional difficulties due to chronic neurological disease. Çocuk Cerrahisi Dergisi 2006; 20: 89-94.

3. Vargün R, Fedakar M, Yağmurlu A. Percutaneous endoscopic gastrostomy: a minimal invasive alternative to open procedure. Çocuk Cerrahisi Dergisi 2006; 20: 95-97.

4. Ackroyd R, Saincher M, Cheng S, El-Matary W. Gastrostomy tube insertion in children: The edmonton experience. Can J of Gastroenterol 2001: 25; 265-268.

5. Arora G, Rockey D, Gupta S. High in-hospital mortality after percutaneous endoscopic gastrostomy: Results of a nationwide population- based study. Clin Gastroenterol Hepatol 2013: 11; 437-444.

6. Aschl G, Kirchgatterer A, Fleischer M, Hinterreiter M, Hubner D, Kranewitter W, et al. e frequency of wound infections after PEG-placement and utilization of glycogel wound dressing: A randomized controlled trial. Wien Klin Wochenschr 2008; 120: 224-227.

7. Avitsland TL, Kristensen C, Emblem R, Veenstra M, Mala T, Bjørnland K. Percutaneous endoscopic gastrostomy in children: A safe technique with major symptom relief and high parental satisfaction. J Pediatr Gastroenterol Nutr 2006; 43: 624-628.

8. Koca T, Sivrice AC, Dereci S, Duman L, Akçam M. Percutaneous endoscopic gastrostomy in children: a single center experience. Turk Pediatri Ars 2015; 50: 211-216.

9. Wilson L, Oliva-Hemker M. Percutaneous endoscopic gastrostomy in small medically complex infants. Endoscopy 2001; 33: 433-436.

10. Loser C, Aschl G, Hebuterne X, Mathus-Vliegen EMH, M Muscaritoli M, Niv Y, et al. ESPEN guidelines on artificial enteral nutrition-percutaneous endoscopic gastrostomy (PEG). Clin Nutr 2005; 24: 848-861.

11. Backman T, Arnbjornsson E, Berglund Y, Larsson LT. Video assisted gastrostomy in infants less than 1 year. Pediatr Surg Int 2006; 22: 243-246.

12. Fortunato JE, Troy AL, Cuffari C, et al. Outcome after percutaneous endoscopic gastrostomy in children and young adults. J Pediatr Gastroenterol Nutr 2010; 50: 390-3.

13. Srinivasan R, Irvine T, Dalzell M. Indications for percutaneous endoscopic gastrostomy and procedure-related outcome. $J$ Pediatr Gastroenterol Nutr 2009; 49: 584-588.

14. Wilson GJ, van der Zee DC, Bax NM. Endoscopic gastrostomy placement in the child with gastroesophageal reflux: is concomitant antireflux surgery indicated? J Pediatr Surg 2006; 41: 1441-1445.

15. Puntis JW, Thwaites R, Abel G, Stringer MD. Children with neurological disorders do not always need fundoplication concomitant with percutaneous endoscopic gastrostomy. Dev Med Child Neurol 2000; 42: 97-99.

16. Fortunato JE, Cuffari C. Outcomes of percutaneous endoscopic gastrostomy in children. Curr Gastroenterol Rep 2011; 13: 293-299. 